\title{
The Creative Project: Design, Implementation, and Assessment
}

\author{
http://dx.doi.org/10.3991/ijep.v6i1.5387 \\ T. L. Larkin \\ American University, Washingtton, DC USA
}

\begin{abstract}
One of the primary objectives in most STEM classrooms is to provide educational experiences that will build and enhance students' ability to think critically and to solve a wide set of different types of problems. To be competitive in the increasingly global society of the twenty-first century, scientists and engineers must often be able to innovate and "think outside the box" when solving a problem or designing a new tool or product. Within a typical STEM classroom, however, assignments often focus primarily on solving textbook-type problems that allow little room for innovation and creative thinking. While these textbook-type problems help students develop their critical thinking skills, they do little for helping them learn to think creatively and innovatively. There is a need for pedagogical activities that include a creative component that would all students to become creative and innovative thinkers. The objective of this paper is to showcase some examples of assessment activities that can be used to facilitate the creative component of student learning in a physics course. The course is entitled Changing Views of the Universe and is often taken by students to satisfy the university's general education requirements towards graduation. The activities assessed in the course include reading quizzes, free-writing assignments, a short paper activity, a creative project, and a final exam. Emphasis will be placed on the design, implementation and assessment of the creative project activity which was first piloted in spring 2014. A discussion related to student perceptions of the activity will be included. In addition, a summary of some of the lessons learned during the implementation phase will be shared.
\end{abstract}

Index Terms-Alternative assessment, authentic assessment, creativity, formative assessment, innovation, student learning, written and oral communication.

\section{INTRODUCTION}

As educators, we must think carefully when designing and developing effective learning tools that will help prepare students for the challenges they will face as they enter the work force. Included in our thinking is the need for critical reflective practice within the context of twentyfirst century learning [1]. To this end, a number of questions naturally arise. These questions include: How can student learning be effectively measured and assessed? Does a student's score on an exam really provide the instructor with a definitive measure of what they have learned and understood? Moreover, can a comprehensive final exam score serve as a summative measure of what students have learned in a course? What can we learn from traditional assessment measures? Do traditional assessment measures really provide us with a robust picture of what students are learning throughout all facets of the learning process? If traditional assessment measures such as the comprehensive final exam can't always provide us with an accurate and definitive measure of student learning, what does? Might an assessment measure that involves a strong creative component serve as an alternative mechanism? Questions such as these furnish the motivation for this paper. Any attempt to answer these questions might best be framed by first posing the broader question, how can a creative project serve to enhance student learning?

\section{CREATIVITY AND STUDENT LEARNING}

Certainly many definitions exist for both creativity and student learning. A definition of creativity might involve the use of imagination and ingenuity particularly in the development of a piece of artwork. A general definition of creativity is typically not presented in tandem with the expansion of scientific knowledge. Interestingly, Csikszentmihalyi, suggests that creativity may be nothing more than a part of the "...normal problem-solving process" [2]. If creativity is indeed a normal part of the problem-solving process, then it seems that more attention could and should be placed on creativity as a portion of the formal education of scientists and engineers. Within the broad field of psychology there are numerous tests and other forms of assessment geared at measuring creativity itself [3]. Nogueira suggests that creativity is something that can serve as an integrated part of the K-college educational system [4]. Sternberg posits that “... creativity is in a large part a decision that anyone can make but that few people actually do make because they find the costs to be too high" [5]. This paper will not focus on measuring creativity as an entity in and of itself; but rather, on describing how a creative project experience may enhance students' content knowledge and fundamentally serve as a motivational component to promote transfer of learning [6].

In a broad sense learning might be considered to be a net gain in understanding, experience, skill and/or expertise pertaining to a particular knowledge set. Adapting their definition from Mayer [7], Ambrose, et al. describes learning as a process that leads to change [8]. In addition, these researchers suggest that the process of learning takes place in the mind of the learner and as a result, we can only infer that it has occurred based on the end products or performances of the students. Learning also involves a change in one's knowledge, beliefs, behaviors, or attitudes. This change is an evolving entity and unfolds over time. As such, change is not transient but rather has a long-term lasting impact on students' thoughts and actions. Ambrose, et al. argues that learning occurs as a result of experience which, in turn, increases the possibility for improved performance and future learning. Collec- 
tively, the active process of creativity in learning is not something we "do" to students. Rather, learning through a creative experiences is something students can and must experience for themselves.

Blamires and Peterson caution that the use of the term creativity in education can be "... slippery, because of its wide-ranging use in society" [9]. As a result, there tends to be some confusion surrounding the concept of creativity in education. Historically, the roots of creativity tend to be grounded in the broader domain of modern psychology. While not a focus of the present paper, this historical grounding is worthy of recognition. When dealing with the topic of creativity, it also possible that what might be considered creative in one subject area might not (or at least to a lesser degree) be considered creative in another. Regardless of the particular subject, Blamires and Peterson suggest that the curriculum can serve as the resource for developing a creative activity that is specific to a particular subject area. In essence, the creativity is dependent upon the pedagogy with the caveat that different pedagogies in different subject areas may foster or hinder creativity.

Within the physics classroom, Guilaran describes a unique creativity-based assignment that makes use of a writing-based component [10]. Using Einstein's special theory of relativity as the specific content area, Guilaran's creative assignment allows students the option of coming up with a problem or novel application that would utilize the theory. Students could also write an original story plot or even submit their own creative assignment with the instructor's approval. In terms of assessment of student creativity, Guilaran simply uses a pass/fail system that depends on how well a student adheres to the assignment instructions. Given that one of the goals of the creative assignments Guilaran offers is to foster the students' selfconfidence and interest in physics, this type of pass/fail assessment is quite appropriate in this particular instance.

As Guilaran's creative activity perhaps illustrates, the art of measuring and assessing student learning continues to be one of the challenges that educators everywhere on the globe face. Combining a creative project along with a writing-based activity can provide a somewhat novel mechanism for the assessment of student learning. The use of writing to enhance and assess student learning within the STEM classroom has a persuasive history [11 - 18].

Unfortunately, students in traditional classrooms often acquire much of their knowledge through passive lectures, textbook reading, and the internet. Passive learning routinely results in students merely trying to learn and regurgitate what the teacher and textbook are telling them. A discouraging fact is, after instruction, students often emerge from our classes with significant misconceptions [19 - 25]. In fact, oftentimes students leave with the same misconceptions that they entered the classroom with! A writing-based approach can be used to effectively help students confront their misconceptions. In addition, formal writing strategies can provide essential "snapshots" to help uncover what students are truly learning as the learning is taking place. Coupling a writing-based approach with a creative project assignment may further provide an additional assessment snapshot into what students are actually learning. Before a discussion of the creative project activity which makes use of this creative coupling is given, a brief overview of the Changing Views course is presented.

\section{ChangIng VIEWS OF THE UNIVERSE}

The Changing Views course is often taken by students to satisfy the university's general education requirements towards graduation and is subscribed to by both STEM majors and non-STEM majors. Non-STEM majors who enroll are typically studying such areas as international relations, business, history, philosophy, literature, the visual arts, communications, and political science. The STEM majors are typically pursuing such areas as computer science, public health, biology, environmental science, mathematics, chemistry, or physics. The fall 2014 class consisted of 47 students. Approximately $80 \%$ of the students who enrolled were not majoring in a STEMrelated field of study. In addition, the course was populated by a fairly even distribution of freshman through senior level students.

The course curriculum offered a broad range of topics to be presented and discussed. A single textbook that covers the unique span of topics does not exist. In the fall 2014 Changing Views class the "textbook" that was used was Coming of Age in the Milky Way by Timothy Ferris [26]. Additional topic-specific journal articles and other readings were also used throughout the course. These readings were often accompanied by a writing-based assignment. These assignments are briefly outlined in a subsequent section. The wide range of topics were presented through multiple venues. For example, course sessions focused on such themes as:

- The Big and the Small

- The Story of Earth

- Ancient Views of the Universe

- The Scientific Revolution: Copernicus, Kepler, Galileo, and Newton

- Gravity through the Lens of Newton

- Pre-Twentieth Century Cosmologies

- What is Light?

- Origin of the Universe: Cosmic Space

- Everything's Relative

A number of guest lecturers in fields such as philosophy, religion, physics, and astrophysics were also invited to speak to the class on topics that included:

- Ancient Greek Views of the Universe from Thales to Plato

- Judeo-Christian Creation Myths and the Theologies Behind Them

- Creativity and Genius: Inside the Minds of Leonardo, Newton, Beethoven and Einstein

- How did the familiar universe of galaxies, stars, and planets come to be? And why do we think we know?

- Planet Hunting, Planet Zoo

Additional topics were explored through two popular video series. These included The Cosmos: A Space-Time Odyssey [27] hosted by Neil deGrasse Tyson and Space, Time and the Universe [28] hosted by Brian Greene.

The topics presented in Changing Views were designed to enhance the course-specific learning outcomes and objectives. These learning outcomes and objectives included the development of an: 
- understanding of fundamental historical, philosophical, and physics concepts, principles, and ideas,

- understanding of major ideas and concepts that have shaped and are shaping $21^{\text {st }}$ century scientific thought and discoveries,

- understanding of the connections between the past, present, and future scientific developments and discoveries that have come to shape our conceptions of the universe,

- understanding and an identification of the major contributions of individual philosophers, scientists, astronomers, mathematicians, historians, etc. who have played a role in helping to develop our conceptions of the universe, and

- appreciation for science and the fundamental laws that govern the universe

To achieve these wide-ranging learning outcomes and objectives, students had the opportunity to demonstrate their understanding through several writing-based assessment activities. These activities included several freewriting activities and short writing-based reading quizzes, a creative project, and a short paper activity. Table I shows the distribution of points that made up the students' course grades.

A brief description of each of the writing-based assessment strategies is included below with particular emphasis on the creative project. Following a description of these activities a summary of the strengths of adopting a writing-based approach will be shared. Particular emphasis is placed on the coupling of the creativity project with a writing-based assessment.

\section{A. Reading Quizzes}

The reading quizzes took on many forms. Ultimately, one goal was to ascertain whether or not the students had completed the assigned reading. In the fall 2014 Changing Views class, most of these assignments were given as take-home activities. While quite short by design, allowing students time outside of class to go back through the assigned reading and write up their responses lent itself to more thorough and thoughtful expressions from the students. Giving the reading quizzes as take-home activities also freed up class time for the presentation of new material.

\section{B. Free-writing Activities}

As part of their homework assignments, students completed approximately 5 - 10 short free-writing activities over the course of the semester. Free-writing and other similar types of activities have been shown to enhance student understanding and motivation to learn [29 - 31]. Upon submission of these activities students received brief, but prompt feedback on their writing. Numerous studies have pointed out the importance and value of prompt and thoughtful feedback to students [32 - 35]. When students take time to reflect on their writing and on the instructor's comments the free-writing activities become a highly effective tool in helping them uncover and then wrestle with their misconceptions while the learning is taking place.

\section{Short Paper}

A short paper assignment served as an additional writing-based assessment tool. This tool is described in more
TABLE I.

POINT DISTRIBUTION FOR COURSE GRADES

\begin{tabular}{|c|c|c|}
\hline Activity & Points Allotted & $\begin{array}{c}\text { Percentage of } \\
\text { Course Grade (\%) }\end{array}$ \\
\hline Reading Quizzes & 150 & 21.9 \\
\hline $\begin{array}{c}\text { Free-writing } \\
\text { Activities }\end{array}$ & 100 & 14.6 \\
\hline Short Paper & 100 & 14.6 \\
\hline Creative Project & 100 & 14.6 \\
\hline Class Involvement & 85 & 12.4 \\
\hline Final Exam & 150 & 21.9 \\
\hline
\end{tabular}

detail in an earlier paper, and only a brief synopsis will be highlighted here [36]. Students were allowed to select their topics pending instructor approval. As part of the assignment, students had to first submit a written proposal outlining the intended topic for their paper following a set of guidelines. The proposals were submitted electronically and rapid feedback was provided by the instructor. In most cases, the students' topics were approved immediately. In a few instances, a student needed additional assistance; not so much in selecting their topic, but rather, in narrowing it down. Allowing the students to select a topic for their papers also served a dual purpose. Selection of a topic that interested them provided the students with additional motivation beyond the fact that they had to do it because a grade was attached. Further, allowing students a choice in selection of their topics insured that there would be a great deal of variety in paper topics. This fact made the grading process very interesting.

Once the proposal phase of the paper writing process was complete, the students were reminded of the rubric that would be used to assess their final papers. The papers were limited to $1200-1500$ words, which translates into approximately $3-4$ double-spaced pages written in $12 \mathrm{pt}$. font. Having a word limit on the papers also served a dual purpose. First, the limit forced students to really get to the point and focus on their topics. Second, the word limit helped curb the grading time required. To thoughtfully comment and provide feedback on a well-written paper took approximately 20 minutes per student. Papers that were sub-par took a little longer, depending on what the specific issue(s) were. Fortunately, there were few papers that fell into this category. Students were encouraged to use their short paper topics as a springboard for their creative project assignments. A more detailed overview of the creative project activity follows in the next section.

\section{The CREATIVE Project}

The creative project activity was implemented to provide students with an opportunity to "think outside the box." Through this activity, students were encouraged to make linkages to material covered in the Changing Views course as well as to their major area of study. It was anticipated that these linkages would facilitate the transfer of learning by helping students make some unique connections between course topics and those they had been exposed to in their major area. The framework for the design, implementation, and assessment of the creative project activity is highlighted in the following subsections.

\section{A. Creative Project Design}

A creative project assignment was developed to allow students an opportunity to creatively express their under- 
standing of a particular topic(s) that had been discussed in class. This activity was given shortly after the midpoint of the semester and in some ways served as a "capstone" project for the students. Students were allowed to select a topic(s) based on the course readings, class lectures and discussions, any of the video segments, or topics that were brought up during the guest lectures. In addition, students were encouraged to consider the topic of their short paper as a springboard for their creative projects. Students were also encouraged to select a topic that might overlap with one or more areas within their major field of study.

\section{B. Project Implementation}

Students were required to submit a proposal, in 250 words or less, that included an overview of their proposed project. Abstracts were submitted electronically through Blackboard [37]. Blackboard is the vehicle used at the university for online posting of assignments, announcements, and general course materials.

In their abstracts students had to make very clear the topic of their project and how it related in some way to topics covered in class. In addition, students had to make clear what the "end product" of their efforts were going to be. Once their proposals had been accepted by the instructor the students set about working on their individual (or in a few cases team) projects.

Students were given considerable leeway as to the type of projects they could do. For example, students were allowed to demonstrate their understanding of their topics through the creation of:

- a piece of artwork,

- some form of musical expression,

- a literary piece,

- a short story,

- a scientific model, machine, instrument or piece of equipment that illustrated a specific concept or idea,

- a short skit or play,

- a short PowerPoint presentation,

- a short video, or even

- something edible.

The above is not an exhaustive list but should give the reader a sense for the broad range of project types and styles that the students were permitted to pursue. The creative projects were actually presented during the final exam time slot with the final exam being given during the last week of regular class. By using the extended time during the final exam time slot, each student was given 3 minutes to present their projects to the class.

\section{Project Assessment}

The projects were assessed based on the original proposal that was submitted, the class presentation, and a 1page written summary of their projects. Table II shows a breakdown of the project's assessment.

Student performance on the creative project activity was very strong with a class average of approximately $93 \%$. The class average on the short paper activity was approximately $84 \%$. Since both activities had a strong writing component, and since students were encouraged to use their short papers as a springboard for their creative projects, a comparison of these two activities is reasonable. While students performed at a strong level on
TABLE II.

Assessment OF THE CREATIVE PROJECT

\begin{tabular}{|c|c|}
\hline Activity & Points Allotted \\
\hline Project Proposal & 15 \\
\hline Final Product & 50 \\
\hline Presentation & 20 \\
\hline Commentary & 15 \\
\hline Total & 100 \\
\hline
\end{tabular}

both activities, they performed at a level almost $10 \%$ higher on the creative project activity. The higher performance level could stem from the fact that the creative project allowed students to "think outside the box" and simultaneously produce an end product that was uniquely their own.

The creative projects developed by the students spanned a wide range of venues. Some examples of the wide-variety of creative projects is illustrated in the next section.

\section{EXAMPLES OF CREATIVE PROJECTS}

The scope and range of the students' creative project topics was very vast and diverse. For example, one student wrote a piece of music and recorded his performance. The recorded piece of music was then the backdrop for a short video presentation that was intended to illustrate the creation of the universe. Another student created a computer simulation of some of the planetary models that had been discussed in class. In fact, several students presented projects that dealt with various planetary models. One project even included a model that was created using cupcakes. This student also brought enough cupcakes to share with the class. Other edible projects included those that demonstrated nutritional needs of astronauts. Some projects had a musical component and involved the actual creation of an ancient musical instrument. The music majors in the class were very excited about being able to merge their major area of study with the creative project assignment. One student built a small telescope that actually worked and another created a model of the Hubble telescope out of PVC materials. This is but a small sampling of the types of projects the students came up with. In the next subsection, a slightly more detailed look at one student's project is illustrated as a segue into a succinct discussion of the project's assessment.

\section{A. Sample Student Creative Project}

Sam, a Public Health major chose to develop a creative project that dealt with ancient medicine. Sam's project was entitled The Sanctuary at Epidaurus. He described Epidaurus as a small city in ancient Greece that was home to the sanctuary of Asklepios. Asklepios, an actual physician in $13^{\text {th }}$ century BCE, was referred to by Homer as the "blameless physician." From the $6^{\text {th }}$ century BCE to the $6^{\text {th }}$ century $\mathrm{CE}$ the cult of Asklepios became quite widespread. The sanctuary itself was a place of both public and private healing. There were many aspects of the healing process including public rituals as well as private sessions that involved both religious healing and physician based methods. To illustrate the sanctuary at Epidaurus, Sam created an animated architectural rendering of the sanctuary that is illustrated in Figure 1. 
PAPER

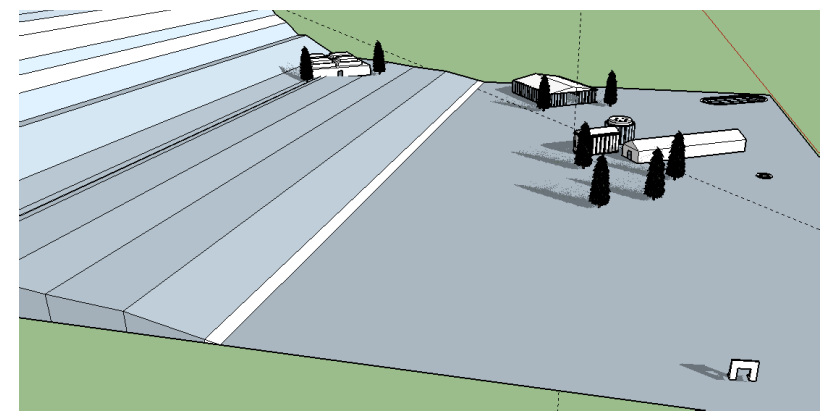

Figure 1. Architectural rendering of the Sanctuary of Epidaurus.

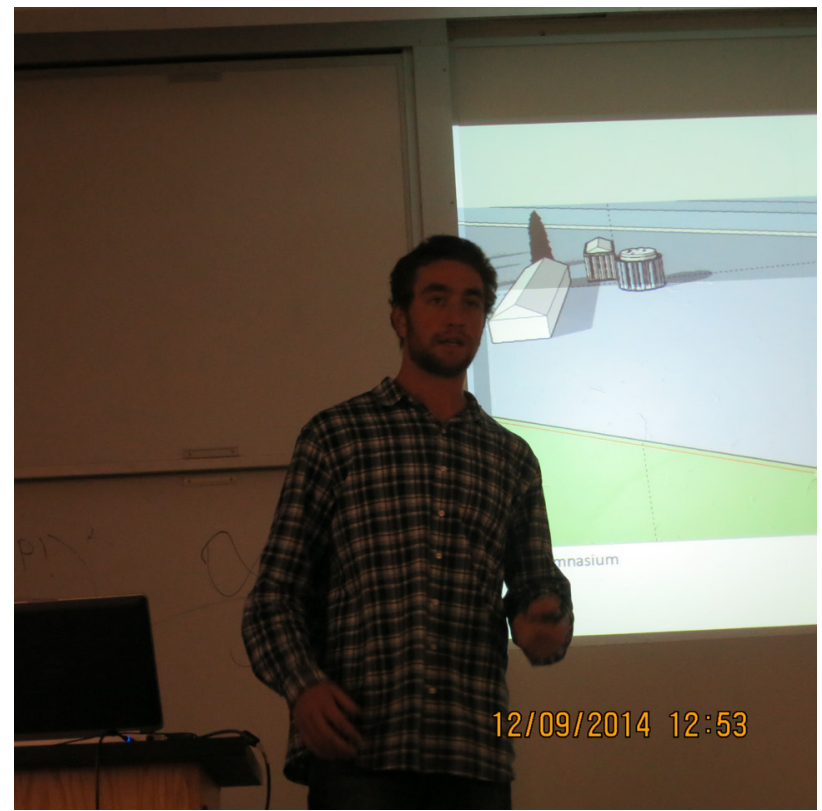

Figure 2. Sam giving his presentation of his project's design.

Figure 2 shows Sam as he highlighted the various elements of his design during his short, 3-minute class presentation. These elements included the architectural rendering of the overview of the sanctuary shown above as well as many other structures. Some of the structures used for healing purposes that Sam illustrated were the propylon (the entrance to the sanctuary), the healing well, the gymnasium/stadium, the banquet hall and hostel building, the thymele (which contained a nonvenomous snake for healing purposes), and the temple and abaton (the buildings where "dream cures" were reported to have happened).

Sam did an excellent job with all aspects of the project and earned full marks in all aspects of the creative project. Through this creative project, Sam was able to merge his interest in public health with ancient medicine. He plans to go on to medical school so this project was particularly appropriate. This topic was also very relevant for this assignment as one aspect of the Changing Views course focused on ancient cultures and views of the universe. Through the project, Sam was also able to enhance his written and oral communication skills through the written proposal, the one-page commentary and the 3-minute class presentation.

Upon conclusion of the class presentations it became quite clear that the students were really "itching" to be able to demonstrate what they had learned through a nontraditional mechanism such as the creative project. In terms of assessment, the creative project provided a somewhat unique mechanism for the instructor to document what students had learned over the course of the semester. Having a 1-page limit on the commentaries and a 3-minute time limit on the oral presentations really forced students to get right to the heart of their topic.

\section{Student Perceptions of the CReative Project ACTIVITY}

The level of enthusiasm for the creative project activity displayed by the students was very high. So many students expressed their pleasure at being able to work on a creative project that focused on a topic that was of particular interest to them. While some students chose to expand upon the topic they had selected for their short papers, many others used this opportunity to explore a totally new topic. Oftentimes, students who chose to focus their projects on an entirely new topic, did so because they had just been exposed to it during a presentation made in a class session that came after the submission of their short papers. Hence, the new topic was selected based on something that students were concurrently learning about in class. Since one of the aims of the project was to help motive student learning and to facilitate the transfer of learning, allowing students to make the choice as to whether to use their short papers as a springboard for their projects or to select an entirely new topic was an important consideration.

It was quite surprising to see how many students chose a new topic for their creative projects. In fact, it would most likely have been much easier for students to use their short paper topics as a springboard since they had already done an extensive amount of research on them. Instead, students often chose to select an entirely new topic, thus creating the need for even more research and work on their part. This fact may serve as one indication of the high motivation levels of the students for doing a creative project.

Based on comments from students on the course evaluations given at the end of the semester, it was very clear that they enjoyed the activity immensely. In addition, several students said that they learned a great deal by being allowed to explore in detail a topic that they were personally interested in. Upon talking with students before, during, and after class as well as during office hours, it was clear that they were incredibly excited about the learning options the creative project activity was offering them. While not initially a primary aim of the project assignment, perhaps the attention it paid to the uniqueness of student learning styles was an added bonus. Because of the unique nature of some of the creative projects, there were some issues that arose, particularly with respect to the use of certain online material. As a result several valuable lessons were learned in terms of how to frame future activities that may involve either a short paper or creative project assignment. In addition, some lessons learned had to do with strategies that would help streamline and shorten the length of time required to grade these kinds of assignments. A summary of the lessons learned is presented in the following section.

\section{LESSONS LEARNED}

As students completed both the short paper and creative project assignments, they were required to do a reasonable amount of research. This research naturally involved using 
PAPER

The Creative Project: Design, IMPLEMENTAtion, AND ASSESSMENT

the library's databases. However, our twenty-first century students often find that digital online resources can be incredibly useful in their research. The use of these online resources raised a couple of issues pertaining to the use of copyrighted information. One lesson learned during the implementation of these assignments was that it is really important to have a science librarian on hand who can answer questions about the citing of online materials whether it be in their short papers or their creative projects and associated commentaries. While issues such as these might appear to be trite; or, they might appear to be something that should simply be left to college writing instructors, they are in fact very real. Students need to have opportunities to utilize the tools they typically receive in a good college writing class. However, requiring students to properly cite reference materials should be an essential element of any assignment that involves a research-based writing component in any course. This task is certainly not exclusive to college writing classes.

While it is probably quite easy to envision the importance of proper citations when writing a research paper, it is quite another for a creative project activity. For example, for their creative projects, some students wanted to make use of music that was digitally available. Others wanted to create their own short film clip using segments of videos readily available online. Because proper citation of any material used was a required component, students often raised questions about how to properly do so, especially regarding digital online media. Once again, a science librarian was contacted to help provide answers regarding ethical and fair use of online materials. The many uncertainties that these sorts of questions raised, were not initially considered in great detail when the creative project assignment was designed and implemented. This was a very important lesson learned and one that will have an impact on the way future assignments of this nature will be constructed for use in the Changing Views course.

An additional lesson learned relates to the potential cost for students to actually create their projects. It was certainly not the aim of the project to cost the students much in out-of-pocket expenses. Hence, it was learned that it was important to let students know this up front when the assignment was given. For example, some students chose to create a model, sketch, sculpture, etc. for their projects. For some of these projects, students had to really innovate in order to find a cost-effective way to actually create their end-product. When the creative project was initially conceived, the design of edible-type projects was included on the list of possible projects. However, during the implementation phase it was learned that food-based projects could be incredibly creative and offer a relatively inexpensive yet very effective end-product. For example, in the spring 2014 class one team of two students researched the nutritional needs of astronauts. To this end, the students created a PowerPoint presentation to use during their short class presentation. In addition, these students made some pudding that they shared with the class that illustrated what they had learned about nutrition needs of astronauts and other potential space travelers.

Another important lesson learned involved the management and assessment of the work that students submitted. For the short paper, it was learned that electronic submissions through the Blackboard portal should be done as an attached Word document. Blackboard provides a "cut-and-paste" option as well, and this turned out to not be an efficient mechanism when it came to grading the submissions. It was learned that an incredible amount of instructor time could be saved by simply having students attach a Word document. The instructor could then use the track changes and comment features available in Word to quickly and easily provide feedback to the students while simultaneously assigning a grade for their assignments. This was a huge timesaver in a class of nearly 50 students!

Most universities use some sort of online platform for communicating with students. As previously noted, the platform used in this instance was Blackboard. Many other similar platforms exist that offer similar options to the ones offered within Blackboard. These platforms are often in a state of continual modification and enhancement on the part of their designers. A final lesson learned is it is important to stay current with the tools available within the online platform. If offered an opportunity to attend a workshop dedicated to the use of the tools available within a particular platform, it is of essential importance to take advantage of it. As faculty we are so often have so many competing tasks and projects on our plates at any given time that it is sometimes difficult to take time out of the day to attend a workshop about an online platform such as Blackboard. However, doing so has long-term benefits, one of which includes a considerable time savings when it comes to assessing and grading students' work. In fact, the most recent version of Blackboard's online platform includes some new antiplagiarism software called SafeAssign. SafeAssign has been designed to prevent plagiarism and to help students learn how to properly credit sources rather than simply paraphrasing them [38]. When an instructor sets up a submission site on Blackboard for a particular assignment, they can select to turn SafeAssign on. When students submit their assignments, they can easily see that it will be run through the SafeAssign system. In addition, instructors can also allow students to see the results once their assignment has been run through the antiplagiarism software. This has served to force students to raise the questions earlier outlined in this section regarding the use of digital and other forms of online media and materials.

\section{SUMMARY}

The Changing Views of the Universe course utilized many writing-based assessment strategies. The aim of each was to assess student learning and understanding using writing as one of the primary vehicles. Employing the very carefully crafted guidelines and instructions for the creative project, students were encouraged to demonstrate their understanding of a key topic(s) covered in the course.

Perhaps it would have been easier for the instructor to simply give the students a multiple choice exam and call it a day. While the primary purpose of an exam is to provide a summative marker of a student's progress in comprehending a subject over a portion of a given term; realistically, it provides merely a single data point regarding student learning. In addition, it does not provide much evidence for transfer of learning. A student's grade on a final exam, for example, does not shed much light on the overall process of learning. If one is truly intent on capturing what a student has learned in a given course, other methods of assessment are required.

The creative project assignment served to motivate students to really engage with the topic they had selected. 
The writing component of the assignment was not lengthy, but served as an excellent mechanism to encourage students to really focus on the central goal of their projects. The writing component also helped to provide a vital connection between the actual creation of the project and the material covered in class. Having a one-page limit on the written commentary really forced students to choose their words carefully and not clutter their writing with unnecessary fillers. The one-page limit also meant that the time the instructor spent grading was minimized and optimized. Hence, the instructor was able to reduce grading time and simultaneously more efficiently assess how the students' commentaries served as a measure of their overall understanding of their projects' main goal(s). This activity was embraced by the students, regardless of their major. Because the assessment included both a written and oral component, a more robust evaluation of student learning was made possible.

It is hoped that the discussion provided here will serve as a catalyst for STEM and other educators to consider including a creative component into their course syllabi. Utilizing the lessons learned from this project might aid in limiting the same sort of questions and issues that came to the surface during the implementation phase describe herein. The creative project activity, in particular may also be an effective way to complement some students' unique learning styles, which is certainly desirable.

\section{ACKNOWLEDGMENT}

The author wishes to thank the students in her fall 2014 Changing Views of the Universe class. In particular, she would like to thank Sam Epstein for graciously allowing his work to be showcased in this article.

\section{REFERENCES}

[1] Benade, L. (2015). Teacher's critical reflective practice in the context of twenty-first century learning. Open Review of Educational Research, 2(1), 42 - 54. http://dx.doi.org/10.1080/23265 507.2014.998159.

[2] Csikszentmihalyi, M. C. (1992). Motivation and creativity. In R. S. Albert (Ed.), Genius \&creativity (pp. 19 - 34). Oxford: Pergamon Press.

[3] Cropley, A. J. (2001). Creativity in education and learning: A guide for teachers and educators. London and New York: RoutledgeFalmer, Taylor and Francis Group.

[4] Nogueira, S. M. (2006). MORCEGOS: A Portuguese enrichment program of creativity pilot study with gifted students and students with learning difficulties. Creativity Research Journal, 18(1), 45 54, http://dx.doi.org/10.1207/s15326934crj1801 6

[5] Sternberg, R. J. (2006). The nature of creativity. Creativity Research Journal, 18(1), 87 - 98, DOI: 10.1207/s15326934 crj1801_10.

[6] Rebello, N. S. (2009). Can we assess efficiency and innovation in transfer? AIP Conference Proceedings, 1179, 241 244. DOI: 10.1063/1.32.66726.

[7] Mayer, R. E. (2002). The promise of educational psychology, volume 2: Teaching for meaningful learning. Upper Saddle River, NJ: Merrill Prentice Hall.

[8] Ambrose, S. A., Bridges, M. W., DiPietro, M., Lovett, M. C., Norman, M. K., (2010). How learning works: 7 research-based principles for smart teaching. San Francisco, CA: Jossey-Bass.

[9] Blamires, M. \& Peterson, A. (2014). Can creativity be assessed? Towards an evidence-informed framework for assessing and planning progress in creativity. Cambridge Journal of Education, 44(2), 147 - 162, http://dx.doi.org/10.1080/0305764X.2013.860 $\overline{081}$

[10] Guilaran, I. J. (2012). Creativity and introductory physics. The Physics Teacher, 50, 42 - 44. http://dx.doi.org/10.1119/1.3670085
[11] Hein, T. L. (1999, May). Using writing to confront student misconceptions in physics. European Journal of Physics, Vol. 20, pp. 137 - 141. http://dx.doi.org/10.1088/0143-0807/20/3/002

[12] Larkin-Hein, T. (2001, January - August). Writing as a teaching and learning tool in SMET education. Journal of SMET Education: Innovations and Research, Vol. 2, Issue 2/3, pp. 25 - 35.

[13] Kalman, C. S. (2007). Successful science and engineering teaching in colleges and universities. Bolton, MA: Anker Publishing Company, Inc.

[14] Larkin, T. L. (2012, February). Closing the loop: What do they do with our feedback? Portuguese Society for Engineering Education (SPEE) Newsletter (Sociedade Portuguesa Para A Educacao Em Engenharia), No. 5, p. 19.

[15] Connolly, P. and Vilardi, T. (1989). Writing to learn mathematics and science. New York: Teachers College Press.

[16] Larkin, T. L. (2010, June). The "write" path to effective student understanding in physics. Annual Conference of the American Society for Engineering Education, Louisville, Kentucky. electronic proceedings.

[17] Teresa L. Larkin (2014, April). The student conference: A model of authentic assessment. International Journal of Engineering Pedagogy (iJEP), Vol. 4, Special Issue, 2, pp. 36 - 46. Kassel University Press GmbH, Kassel, Germany. eISSN: 2192-4880. http://dx.doi .org/10.3991/ijep.v4i2.3445.

[18] Teresa L. Larkin (2015, May). A rubric to enhance student writing and understanding. International Journal of Engineering Pedagogy (iJEP), Vol. 2, Special Issue, 2, pp. 12 - 19. Kassel University Press GmbH, Kassel, Germany. eISSN: 2192-4880. http://dx. doi.org/10.3991/ijep.v5i2.4587.

[19] Arons, A. B. (1990). A guide to introductory physics teaching. New York: John Wiley \& Sons.

[20] Halloun, I. A. and Hestenes, D. (1985). The initial knowledge state of college students. American Journal of Physics, 53(11), 1043 - 1055. http://dx.doi.org/10.1119/1.14030

[21] McCloskey, M., Caramazza, A., and Green, B. (1980). Curvilinear motion in the absence of external forces: Naïve beliefs about the motion of objects. Science, 210, 1139 - 1141. http://dx.doi.org/10.1126/science.210.4474.1139

[22] McDermott, L. C. (1984). Research on conceptual understanding in mechanics. Physics Today, 37, 24 - 32. http://dx.doi.org/10.1063/1.2916318

[23] McDermott, L. C. (1991). A view from physics. In M. Gardner, J. Greeno, F. Reif, A. H. Schoenfeld, A. diSessa, and E. Stage (Eds.), Toward a scientific practice of science education (pp. 3 30). Hillsdale, NJ: Lawrence Erlbaum Associates.

[24] Hammer, D. (1996). More than misconceptions: Multiple perspectives on student knowledge and reasoning, and an appropriate role for educational research. American Journal of Physics, 64, 1316 1325. http://dx.doi.org/10.1119/1.18376

[25] Reif, F. (1995). Millikan lecture 1994: Understanding and teaching important scientific thought processes. American Journal of Physics, 63(1), 17 - 32. http://dx.doi.org/10.1119/1.17764

[26] Ferris, T. (2003). Coming of age in the Milky Way. New York, NY: Perennial: An Imprint of HarperCollins Publishers.

[27] Druyan, A., MacFarlane, S., Cannold, M., Braga, B., and Clark, J. (Executive Producers). (2014). The cosmos: A spacetime odyssey [Video Series]. Beverly Hills, CA: Twentieth Century Fox.

[28] Apsell, P. S. (Senior Executive Producer), \& Ritsko, A. (Managing Director). (2012). Space, time, and the universe [Video Series]. United States: PBS Distribution.

[29] Ref. 12.

[30] Ref. 13.

[31] Ref. 14.

[32] Brown, S. \& Knight, P. 1994. Assessing learners in higher education. London: Kogon Page.

[33] Gastel, B. 1991. Teaching science: A guide for college and professional school instructors. Phoenix, AZ: Onyx Press.

[34] Harmelink, K. 1998. Learning the write way. The Science Teacher, 65(1), $36-38$.

[35] Wiggins, G. 1997. Feedback: How learning occurs. AAHE Bulletin, 50(3), 7 - 8. 
[36] Larkin, T. L. (2015). Teaching Outside the Discipline: A STEMRelated Course in a Non-STEM Curricular Area. $122^{\text {nd }}$ Annual Conference of the American Society for Engineering Education. Seattle, WA. Article published in electronic proceedings. http://dx.doi.org/10.18260/p. 24818

[37] http://www.blackboard.com/, accessed 06.01.15.

[38] www.safeassign.com, accessed 12.19.15.

\section{AUTHOR}

T. L. Larkin is an Associate Professor of Physics Education in the Physics Department at American University, Washington, DC 20016 USA. She serves as Director and of the Dual-Degree Engineering program in affiliation with Columbia University's Fu Foundation School of Engineering and Applied Science. (e-mail: tlarkin@american.edu)

This article is an extended and modified version of a paper presented at the International Conference on Interactive Collaborative Learning (ICL2015), held 20-24 December 2015, in Florence, Italy. Submitted 19 December 2015. Published as resubmitted by the author 28 January 2016. 